\section{Regards sur l'économie allemande}

Bulletin économique du CIRAC

$97 \mid 2010$

Varia

\title{
Autonomie tarifaire
}

BISPINCK Reinhard, SCHULTEN Thorsten (eds), Zukunft der

Tarifautonomie. 60 Jahre Tarifvertragsgesetz : Bilanz und Ausblick

\section{(2) OpenEdition}

\section{Journals}

Édition électronique

URL : http://journals.openedition.org/rea/4153

DOI : $10.4000 /$ rea. 4153

ISBN : 978-2-8218-0890-4

ISSN : 1965-0787

Éditeur

CIRAC

\section{Édition imprimée}

Date de publication : 1 juillet 2010

Pagination : 35

ISSN : 1156-8992

Référence électronique

«Autonomie tarifaire », Regards sur l'économie allemande [En ligne], 97 | juillet 2010, mis en ligne le 13

juillet 2010, consulté le 22 septembre 2020. URL : http://journals.openedition.org/rea/4153; DOI :

https://doi.org/10.4000/rea.4153

Ce document a été généré automatiquement le 22 septembre 2020.

(c) CIRAC 


\section{Autonomie tarifaire}

BISPINCK Reinhard, SCHULTEN Thorsten (eds), Zukunft der

Tarifautonomie. 60 Jahre Tarifvertragsgesetz : Bilanz und Ausblick

\section{RÉFÉRENCE}

BISPINCK Reinhard, SCHULTEN Thorsten (eds), Zukunft der Tarifautonomie. 60 Jahre Tarifvertragsgesetz : Bilanz und Ausblick, VSA-Verlag, Hambourg, 2010, 214 p.

1 Cet ouvrage tombe à point nommé pour mieux comprendre la portée de la décision du Tribunal fédéral du Travail de rompre avec sa jurisprudence passée qui érigeait en principe la convention unique de branche. Il dresse un bilan de cette Loi sur les conventions tarifaires qui avait été adoptée le 9 avril 1949, peu avant la constitution de la République fédérale, et qui, pendant 60 ans, a été garante de "paix sociale » outreRhin. Et il cherche à en tracer les perspectives d'avenir, rassemblant là les principales contributions à un symposium organisé à l'occasion de l'anniversaire de la loi par le DGB et l'Institut WSI auprès de la Fondation Hans-Böckler. Les réflexions tournent toutes autour d'une question centrale: comme "re-stabiliser» le système de la convention de branche, alors que les mutations économiques ont modifié la base sur laquelle il est établi : le périmètre des branches. 